\title{
Black Holes and
}

the Structure of the Universe 


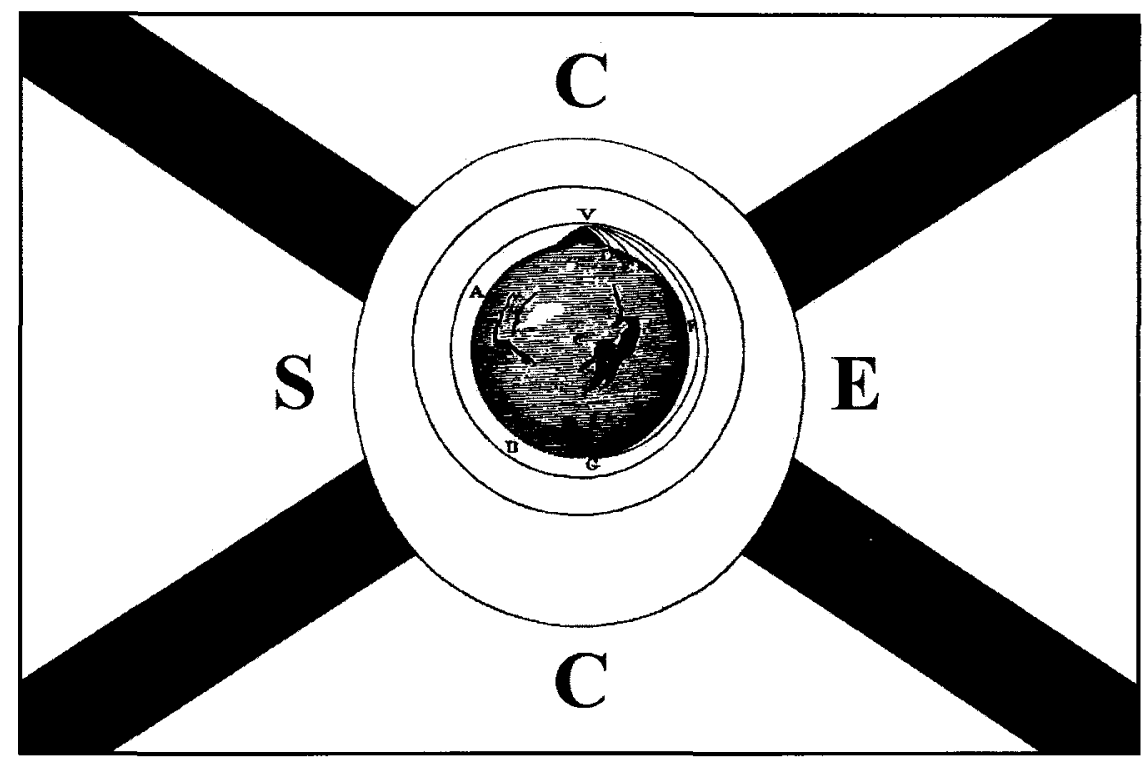

Published by World Scientific Publishing Co. in association with the Centro de Estudios Cientificos (CECS), Valdivia, Chile 


\section{Black Holes and}

\section{the Structure of}

the Universe

\section{Editors \\ Claudio Teitelboim \\ Jorge Zanelli}

Centro de Estudios Científicos (CECS)

Valdivia, Chile 


\section{Published by}

World Scientific Publishing Co. Pte. Ltd.

P O Box 128, Farrer Road, Singapore 912805

USA office: Suite 1B, 1060 Main Street, River Edge, NJ 07661

UK office: 57 Shelton Street, Covent Garden, London WC2H 9HE

\section{British Library Cataloguing-in-Publication Data}

A catalogue record for this book is available from the British Library.

\section{BLACK HOLES AND THE STRUCTURE OF THE UNIVERSE}

Copyright $\odot 2000$ by World Scientific Publishing Co. Pte. Ltd.

All rights reserved. This book, or parts thereof, may not be reproduced in any form or by any means, electronic or mechanical, including photocopying, recording or any information storage and retrieval system now known or to be invented, without written permission from the Publisher.

For photocopying of material in this volume, please pay a copying fee through the Copyright Clearance Center, Inc., 222 Rosewood Drive, Danvers, MA 01923, USA. In this case permission to photocopy is not required from the publisher.

ISBN $981-02-4269-7$

Printed in Singapore. 


\section{CONTENTS}

Preface vii

Higher Dimensional Chern-Simons Theories and Topological Black Holes 1 M. Bañados

Wormholes on the World Volume: Born-Infeld Particles and

Dirichlet p-Branes

G. W. Gibbons

Evaporation of Primordial Black Holes

S. W. Hawking

Fermion Models and Chern-Simons Theories

F. A. Schaposnik

Uniqueness of $\mathrm{D}=11$ Supergravity

S. Deser

Probing Black Holes and Relativistic Stars with Gravitational Waves K. S. Thorne

Chern-Simons Supergravities with Off-Shell Local Superalgebras R. Troncoso and J. Zanelli 
This page is intentionally left blank 


\section{PREFACE}

The extreme geography of Chile and of Antarctica were the settings for sessions of the meeting on "Black Holes and the Structure of the Universe", from which this volume stems.

The meeting, held in August 1997, was made possible by a joint effort in which the government, the private sector and the Chilean Air Force, among others, took part. This common will for the cause of science and the understanding of the Universe meant much for the society at large in a country still confronting divisions from the past. To all those who made it possible, especially the participants and the speakers who came from all over the world, we extend our profound gratitude.

C. Teitelboim and J. Zanelli 